\title{
ESTRATÉGIAS DE AVALIAÇÃO EM DISCIPLINAS DE ENGENHARIA FEITAS A DISTÂNCIA: SOLUÇÕES ENCONTRADAS DURANTE A PANDEMIA DA COVID-19
}

\author{
DOI: 10.37702/2175-957X.COBENGE.2021.3413
}

Miguel Angel Calle Gonzales - miguel.calle@ufabc.edu.br Universidade Federal do ABC Av. dos Estados 5001 09210-580 - Santo André - SP

Resumo: A situação pandêmica na atualidade acabou mudando drasticamente a forma de trabalhar dos professores de engenharia forçando-os a migrar à modalidade de aulas a distância. Diversas ferramentas tecnológicas de comunicação virtual e postagem de vídeos online acabou facilitando a transmissão das aulas para os alunos. Contudo, a forma de avaliar o conteúdo assimilado pelo aluno nas aulas acabou surgindo como um dos maiores desafios, especialmente para professores com pouca familiaridade com as aulas a distância. Neste trabalho são apresentadas treze estratégias para avaliação do aluno em aulas a distância desenvolvidas especificamente para disciplinas na área de engenharia mecânica. O uso destas ferramentas evidenciou um alto interesse, engajamento e boa aceitação por parte dos alunos que repercutiu não só no maior desempenho deles, mas também na alta qualidade dos trabalhos desenvolvidos por eles.

Palavras-chave: estratégias de avaliação, ensino a distância, engenharia 


\section{ESTRATÉGIAS DE AVALIAÇÃO EM DISCIPLINAS DE ENGENHARIA FEITAS A DISTÂNCIA: SOLUÇÕES ENCONTRADAS DURANTE A PANDEMIA DA COVID-19}

\section{INTRODUÇÃO}

A situação pandêmica que enfrenta o mundo na atualidade acabou mudando drasticamente o estilo de vidas das pessoas e particularmente a forma de trabalhar dos professores de engenharia nas universidades do Brasil. O trabalho remoto virou a ordem do dia e aulas concebidas e ministradas por muitos anos de forma presencial precisaram ser adaptadas forçosamente para ser ministradas a distância. $O$ fato de dispor nos dias de hoje de diversas ferramentas tecnológicas de comunicação virtual e postagem de vídeos online acabou facilitando a produção e apresentação das aulas em forma de vídeos para os alunos com boa qualidade seja na forma síncrona como assíncrona. Por outro lado, uma das maiores dificuldades que na modalidade das aulas a distância é a forma de avaliar o conteúdo assimilado pelo aluno tanto nas aulas como na disciplina como um todo. Esta dificuldade se agrava especialmente para professores com pouca familiaridade com a modalidade de aulas a distância e cujo primeiro contato se deve principalmente à situação pandêmica atual.

A avaliação é um processo muitas vezes discutido, questionado e até criticado por diversos agentes de educação em geral. Apesar disso, o processo de avaliar o aluno para atribuição de nota é amplamente usado como critério de aprovação ou desaprovação assim como para indicar se o aluno teve um desempenho regular, bom ou excepcional. Por outro lado, o processo de avaliação pode ser aproveitado para dar uma melhor autopercepção ao aluno de estar ou não assimilando os conteúdos passados em aula enquanto está trilhando a disciplina (Piletti, 1987). Nesse sentido, o processo de avaliação pode ser integrado como parte inseparável da metodologia de ensino em cada aula e na disciplina completa de forma a verificar a participação do aluno na aula, identificar suas dificuldades, engajá-lo nos trabalhos propostos, dar condições/feedback para realiza-los e, finalmente, Ihes atribuir nota (Severo Santos, 2006; Rocha, 2014; Zabala, 2015; NETEL, 2020).

O processo de avaliação pode ainda ter objetivos diferentes em função do grau de assimilação dos conceitos passados em aula, ou seja, se o aluno lembra, sabe, consegue reproduzir e se consegue aplicar tais conceitos. Graus de assimilação muito mais profundos na aplicação de conceitos demandam mais tempo de aprendizagem empregando, por exemplo, atividades práticas junto com meios de comunicação efetivos entre aluno e professor para proporcionar feedback (Pimentel, 2020). Contudo, estas atividades práticas não poderiam ser utilizadas para a mera avaliação da participação dos alunos em cada aula devido ao longo tempo que cada aula demandaria ao aluno pelo que seria inviável. Vale dizer que a falta de uma estratégia de avaliação que corrobore a assiduidade dos alunos às aulas leva inevitavelmente, com o tempo, ao relaxamento e falta de compromisso dos estudantes com a participação nas aulas como evidenciado em disciplinas completamente ministradas com aulas síncronas sem avaliação da participação.

Neste trabalho são apresentadas treze estratégias práticas para avaliação do desempenho dos alunos aplicadas a disciplinas de engenharia baseadas na experiência didática do autor deste trabalho durante o período de pandemia.

\section{ESTRATÉGIAS DE AVALIAÇÃO}

As aulas a distância foram ministradas pelo autor deste trabalho completamente na modalidade assíncrona, ou seja, as aulas foram previamente gravadas em forma de 
videoaulas de curta duração e disponibilizadas aos alunos (junto com material complementar também em forma de vídeos) em site desenvolvido de forma dedicada. As estratégias de avaliação foram baseadas na experiência didática do autor deste trabalho ministrando disciplinas ligadas a processos de fabricação e o uso de ferramentais computacionais em aplicações de engenharia. As disciplinas foram configuradas para terem aulas teóricas, aulas práticas e trabalho final onde cada uma delas vinculadas a uma estratégia de avaliação.

As estratégias de avaliação foram organizadas e apresentadas no Quadro 1. Estas estratégias foram idealizadas considerando a avaliação de: 1) a aula ordinária para corroborar que o aluno assistiu a aula e absorveu minimamente o seu conteúdo, 2) a aula prática que demanda o uso prático de ferramentas computacionais para colocar em evidência, de forma prática, num caso particular o conteúdo absorvido nas aulas ordinárias que que acaba tendo um peso maior que as aulas ordinárias por requerem uma maior dedicação de tempo, e 3) o trabalho final que envolve a corroboração da mínima capacitação que o aluno atingiu em relação ao conteúdo passado na disciplina por meio de um projeto que evidencie o domínio e uso de uma pequena ou grande parte do conteúdo passado na disciplina inteira.

Quadro 1 - Estratégias de avaliação

\begin{tabular}{|l|l|l|}
\hline$\#$ & Estratégias de avaliação & Tempo execução \\
\hline 1 & Ferramentas de comunicação & $20 \mathrm{~min}$ \\
\hline 2 & Enquetes & $20 \mathrm{~min}$ \\
\hline 3 & Questionários & $30 \mathrm{~min}$ \\
\hline 4 & Redação de conceitos & $20 \mathrm{~min}$ \\
\hline 5 & Exercícios gráficos & $20 \mathrm{~min}$ \\
\hline 6 & Exercícios de cálculo & $30 \mathrm{~min}$ \\
\hline 7 & Visitas virtuais & 1 hora \\
\hline 8 & Documentários, realities e conteúdos & 1 hora \\
\hline 9 & Webinars e artigos & 1 hora \\
\hline 10 & Miniprojetos & 1 hora \\
\hline 11 & Atividades práticas e tutoriais & 10 horas \\
\hline 12 & Relatórios & 10 horas \\
\hline 13 & Apresentação oral & 10 horas \\
\hline
\end{tabular}

Fonte: próprio autor

O que define a aplicação de uma estratégia ou outra (tanto nas aulas como trabalho final da disciplina) é o tempo aproximado que é demandado para sua execução. O tempo aproximado que é esperado para o desenvolvimento das atividades é também apresentado no Quadro 1. Em continuação, são descritos cada uma destas estratégias com maior detalhe.

\subsection{Ferramentas de comunicação}

Provavelmente uma das mais importantes formas de avaliação do desempenho do aluno numa disciplina a distância. Uma das maiores deficiências no ensino a distância radica no distanciamento físico do professor e aluno dando a impressão que o aluno está por conta própria sem a presença do professor. Disponibilizar ferramentas de comunicação do professor com os alunos (e inclusive entre os alunos) como e-mail, fóruns, aplicativos de mensagens instantâneas (exemplo: WhatsApp), chats e murais não somente proporciona uma maior diversidade de meios de apoio didático aos alunos, mas também serve como uma forma de avaliar indiretamente a participação, engajamento e dificuldade ao longo da disciplina. Esses meios de comunicação podem ser usados para postagem de comunicados gerais, aviso de liberação de aulas, questões relacionadas ao desenvolvimento das atividades e conteúdo das aulas, postagem de feedback de atividades 
práticas, postagem de gabaritos de exercícios já encerrados, solução de problemas técnicos e individuais, comentários. Alunos com grande participação nestes meios são mais fáceis de acompanhar do que outros que não participam. Nesse sentido, alunos menos participativos devem ser avaliados de outras formas. A Figura 1 mostra parte do mural (Padlet) para desenvolvimento do projeto CAD/CAE/CAM (com tema de livre escolha do aluno) usado para postagens de dúvidas e feedback do professor (foram um total de 49 postagens sobre dúvidas do trabalho prático em 2020).

Figura 1 - Mural de feedback de atividade prática com 49 postagens de alunos.

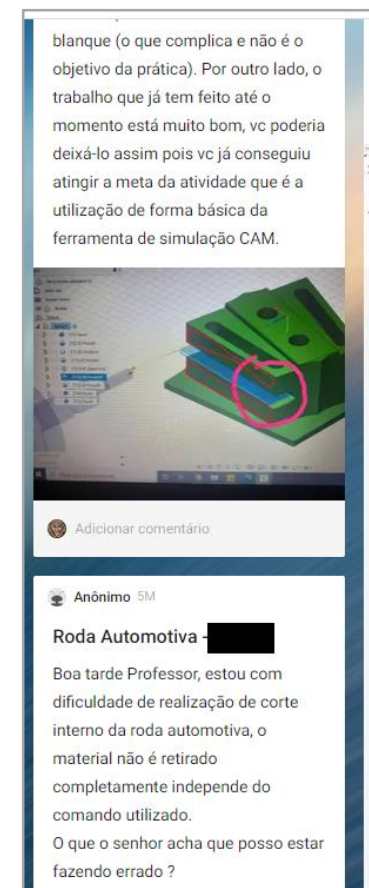

fazendo errado?
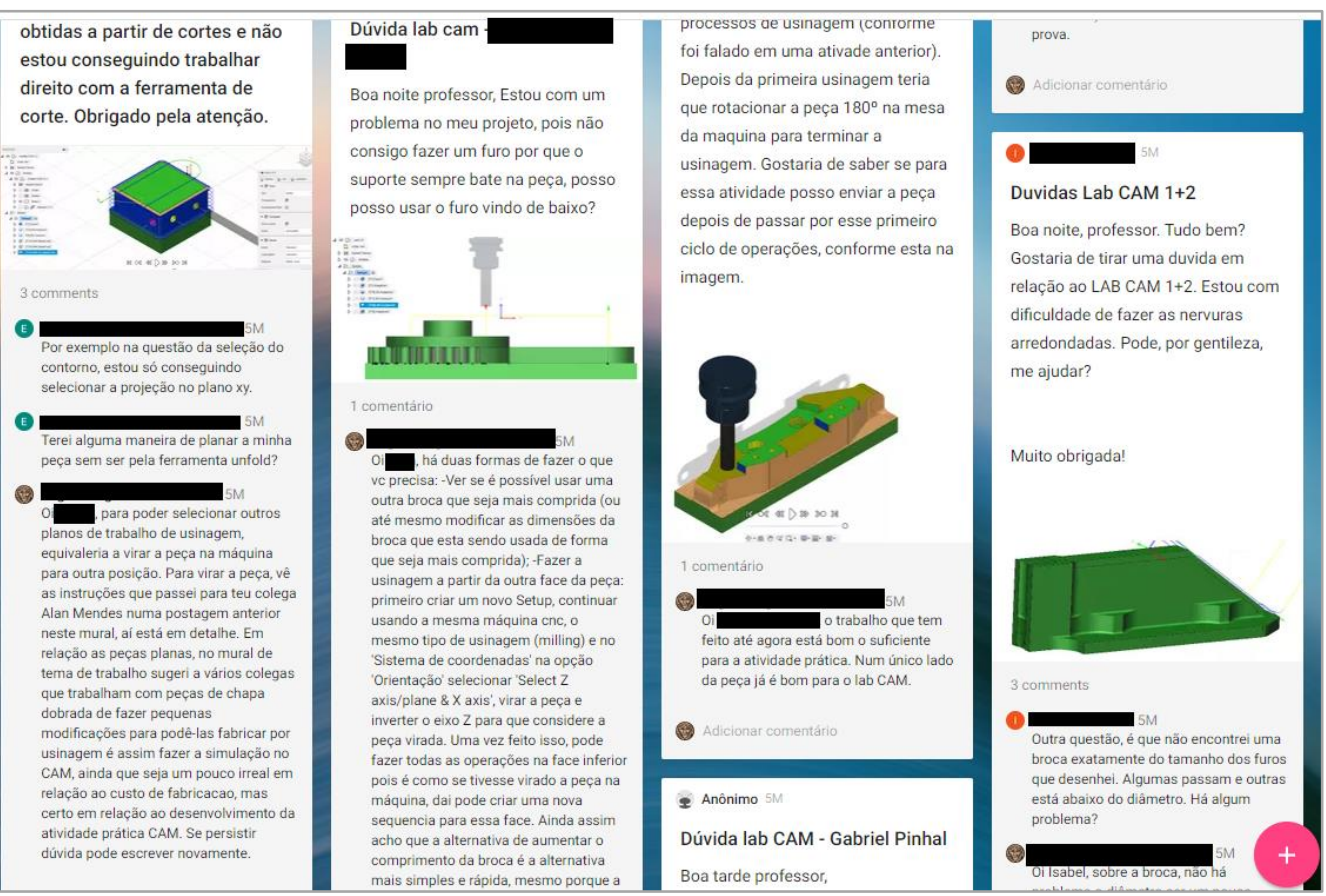

Fonte: próprio autor

\subsection{Enquetes}

Enquetes no início e no final da disciplina são boas oportunidades para o professor ter uma ideia melhor do ponto de vista do aluno, como por exemplo, se ele acha adequado o formato da plataforma digital proposta para a disciplina, suas expectativas em relação ao que vão (e gostariam) de aprender durante as aulas, sugestões, críticas, feedback, etc. Estas informações, além de quebrar o gelo e envolver logo de início de forma participativa ao aluno, também proporcionam um ótimo feedback para implementação de melhorias contínuas na disciplina.

\subsection{Questionários}

Questionários provavelmente uma das formas mais simples de poder avaliar e acompanhar o conhecimento absorvido pelos alunos em cada aula. As perguntam podem ser formuladas de forma que o aluno tenha que escolher a opção correta dentre várias alternativas. As modalidades de questionamento podem ser feitas de múltipla escolha, relacionar conceitos, verdadeiro ou falso, seleção de mais de uma alternativa correta, etc. As questões não precisam ser limitadas a repetir conceitos nas exatas palavras como vistos em aula, mas devem incluir questões que envolvam um determinado grau de assimilação para transferir tais conceitos em questões mais práticas, por exemplo: colocar situações 
reais ou fictícias e pedir indicar melhor solução de acordo com o visto em aula, perguntas que vão além do visto em aula requerendo uma interpolação de conceitos, perguntas que envolvem diferenciação clara de conceitos diferentes entre outras formas. O google formulários possui uma ferramenta muito simples e potente para elaboração e preenchimento deste tipo de questionário.

\subsection{Redação de conceitos}

A avaliação é importante porque ajuda a evidenciar se o aluno entendeu eu não os conceitos vistos em aula. Uma das formas de poder corroborar isso é pedir para o aluno (como parte de uma avaliação) redigir o que entendeu sobre um conceito, teoria ou tema visto em aula. Deve se levar em conta que cada aluno irá redigir nas suas próprias palavras o que entendeu. Nesse sentido, o mais importante é perceber se ele não está interpretando alguma informação de forma errada que possa acarretar erros graves ao invés de julgar se ele escreveu de uma determinada maneira ou não. A redação pode envolver também escrever sobre diferenças/semelhanças entre dois conceitos, exemplos/identificação de aplicação de conceitos na vida real, opiniões, etc. Esta redação pode fazer parte de formulários também.

\section{$2.5 \quad$ Exercícios gráficos}

Os exercícios gráficos envolvem o desenvolvimento de esboços, diagramas, desenhos e esquemas para que o aluno apresente conceitos de forma visual e nítida. Estes exercícios demandam um certo grau de assimilação do conteúdo e lógica para sua elaboração. Por exemplo, esboços de componentes para evidenciar conceitos aplicados, diagramas de hierarquia de conceitos, diagrama de PERT/Gantt/etc., desenhos de sistemas elétricos/pneumáticos/etc., esquemas para organização de informações para apresentação de forma clara, etc. Estes exercícios quando vinculados às aulas podem ser resumidos a exercícios gráficos curtos que só evidenciem uma compreensão básica dos conceitos vistos em aula e não necessariamente um aprofundamento maior. Os gráficos desenvolvidos pelos alunos podem ser fotografados, escaneados ou esboçados num programa de computador (programas básicos que não envolvam um processo de instalação adicional) para depois ser anexado a formulários.

\subsection{Exercícios de cálculo}

Exercícios de cálculo podem ser explorados na avaliação de conteúdo teórico onde existem formulações matemáticas ligadas ao cálculo de parâmetros ou variáveis. Quando o intuito é basicamente avaliar a absorção dos conceitos numa determinada aula com cálculo, precisa ter cuidado em não complicar muito as questões de cálculo para o aluno não acabar focado no cálculo matemático ao invés do sentido de aplicação da formulação matemática em questão. Perguntas simples, diretas e que muitas vezes podem ser feitas de cabeça podem ser recomendadas para reforçar o foco nos conceitos e não na dificuldade de cálculo matemático. Já perguntas mais elaboradas podem ser desenvolvidas no papel, escaneadas ou fotografadas e anexadas ao formulário para corroborar que o aluno fez o cálculo ou chegou perto e ganhar nota parcial. Já questões de cálculo mais complexas podem ser desenvolvidas em planilhas Excel, em forma de tabelas de dados preferencialmente junto com gráficos ambos anexados ao formulário para agilizar o processo de revisão. A Figura 2 mostra um exercício de cálculo para estimar a curva tensão deformação de um material baseado num teste de tração real descrito em forma de vídeolaboratório (teste tração, aquisição experimental de fotos de teste, análise de correlação digital de fotos para avaliação de deformações reais e resultados). Logo, os alunos com os dados obtidos calculam a curva de tensão-deformação em planilha e de forma gráfica. 
Figura 2 - Exercício de cálculo de curva tensão deformação baseada em experimento.
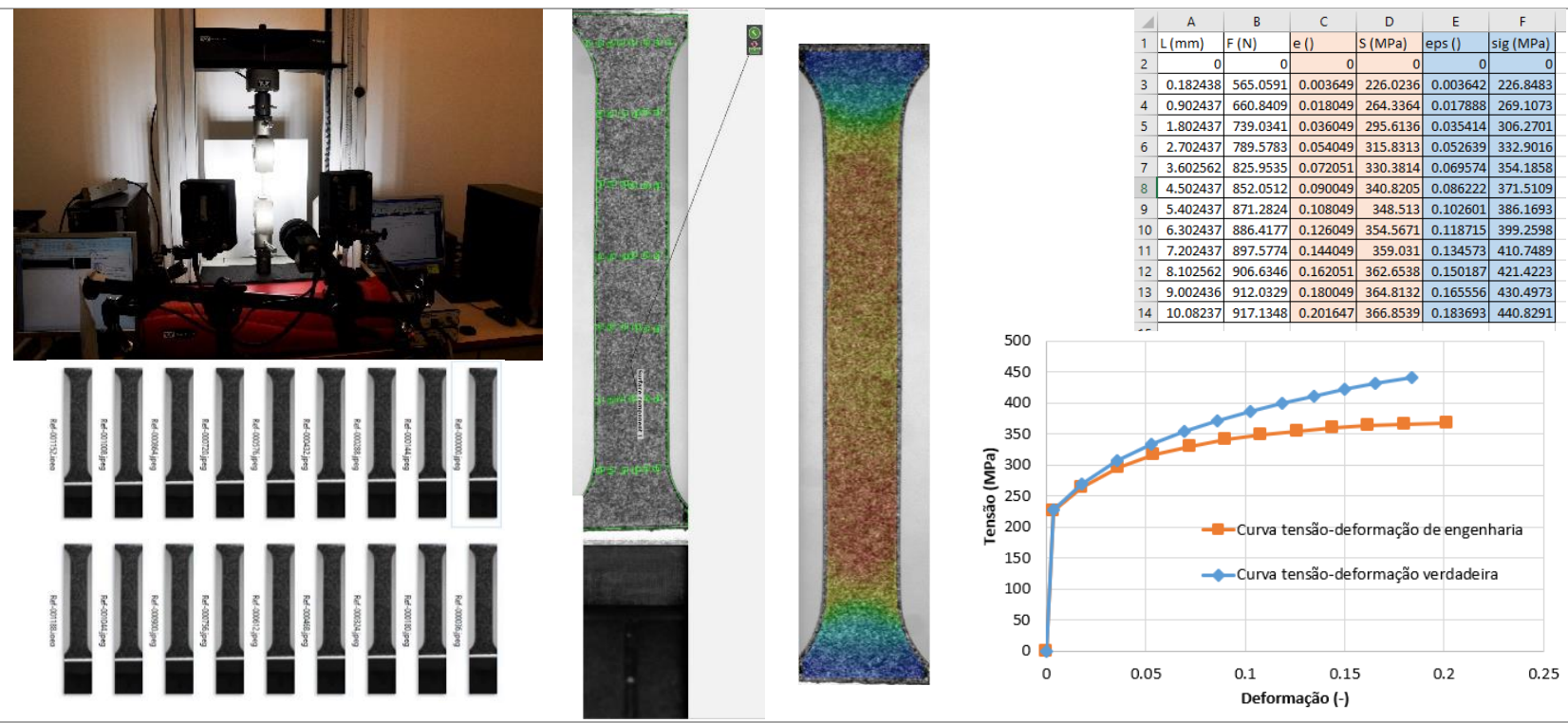

Fonte: próprio autor

\subsection{Visitas virtuais}

Dentre as medidas de contenção da pandemia, o isolamento social foi uma medida que acabou trazendo grandes limitações e reconfiguração das atividades práticas desenvolvidas nas disciplinas de engenharia. Ainda que muito diferente de visitas presenciais em grupo a centros de pesquisa, empresas, centros industriais, etc., a visita virtual acabou se transformando em mais uma alternativa para os alunos poderem ter experiência de conhecer outros ambientes professionais. Uma vantagem das visitas virtuais é poder ter acesso a ambientes professionais do outro lado do mundo sem que isso envolva gastar mais tempo de deslocamento ou dinheiro. Vídeos de visitas guiadas a grandes indústrias e centros de pesquisa para conhecer diversas tecnologias de engenharia podem ser encontrados na internet. A avaliação da experiência dos alunos nestas visitas pode compreender um questionário, preencher uma lista ou, inclusive, o desenvolvimento de um mini relatório. Figura 3 mostra um vídeo postado no youtube.com sobre visita à fábrica JLCPCB localizada na China para ver a fabricação de circuitos impressos. 
Figura 3 - Visita virtual a fábrica chinesa JLCPCB de placas de circuitos impressos.

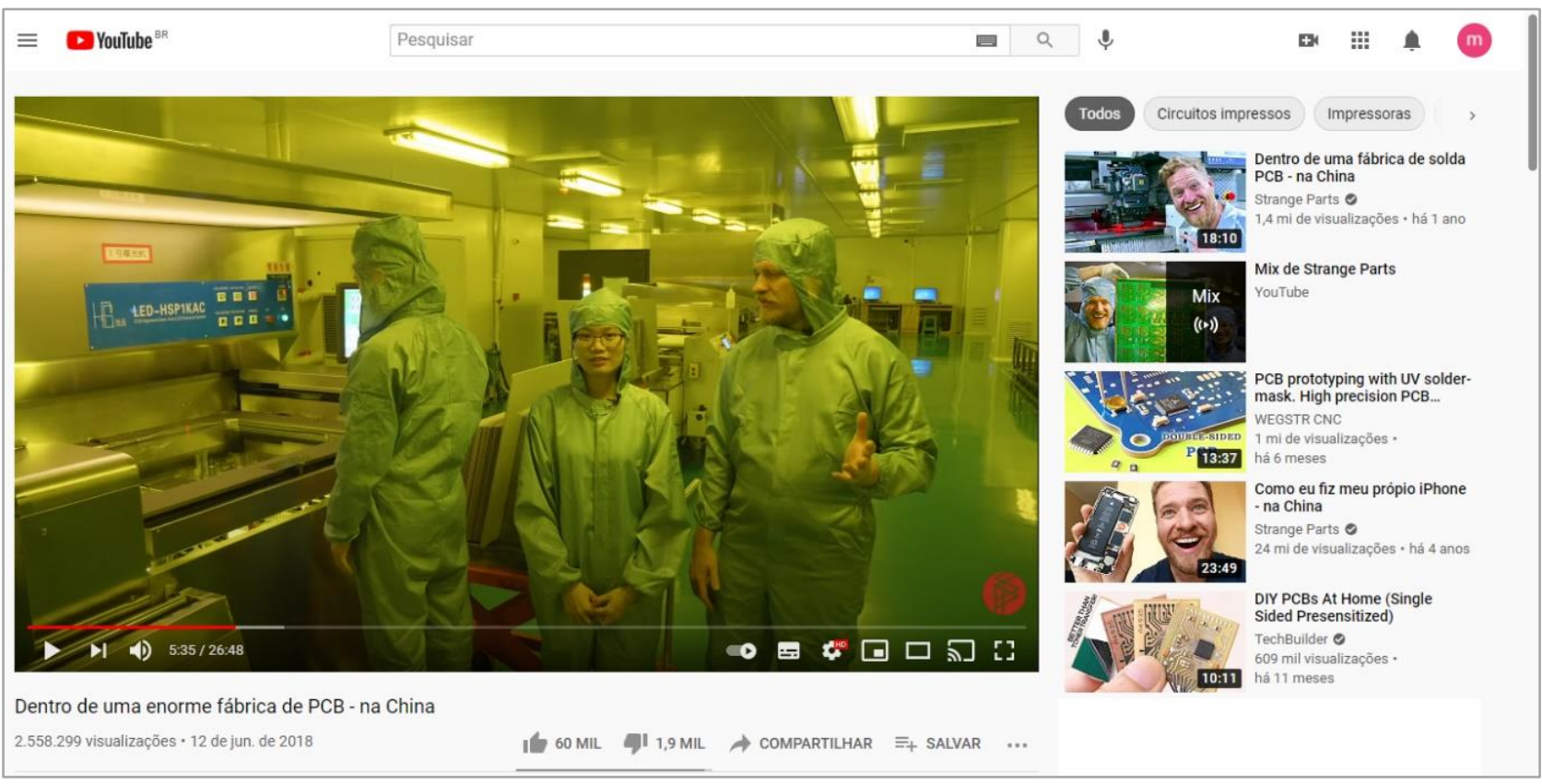

Fonte: Strange Parts - youtube.com

\subsection{Documentários, realities e conteúdo}

Existem uma grande quantidade de conteúdo na internet produzido para TV e para internet com muito boa qualidade e que pode ser explorado para desenvolvimento de aulas práticas. Documentários sobre design e/ou fabricação, desafios tecnológicos, novidades de engenharia, história da ciência, casos investigativos de engenharia, realities com desafios tecnológicos de design e/ou fabricação, conteúdo sobre design/fabricação/aplicação/manutenção/restauração postados com certa regularidade são exemplos de material que poderia ser utilizado numa atividade prática. A grande quantidade de material disponível na internet possibilita que este tipo de atividade possa ser desenvolvido pelos alunos com tema de livre escolha de acordo com os interesses particulares do aluno o que traz mais um incentivo para o seu engajamento e desenvolvimento. A avaliação pode envolver também um questionário ou mini relatório.

\subsection{Webinars e artigos}

O conteúdo das aulas numa disciplina está diretamente vinculado ao descrito na ementa da disciplina e parte do trabalho do professor é poder criar material didático básico para ser usado como ferramenta de ensino contemplando este conteúdo. Diversos temas listados na ementa das disciplinas são estudados de forma básica e não profundamente por limitações inerentes de carga horária. Esses temas muitas vezes podem ser disponibilizados como material complementar para alunos que desejam se aprofundar em forma de webinars e artigos técnicos/científicos especializados e focados nesses temas específicos. $\mathrm{O}$ intuito do material complementar não atingir todos os alunos, mas àqueles que tem um interesse específico no tema, tem curiosidade ou simplesmente para quem tem um pouco mais de tempo que pode ser utilizado para aperfeiçoar seus conhecimentos e se familiarizar com temas mais complexos. A avaliação, se tiver, pode consistir num questionário ou numa breve redação. 


\subsection{Miniprojetos}

Os miniprojetos acabam sendo uma atividade que visa dar mais liberdade e flexibilidade ao aluno para usar diversas ferramentas de pesquisa e desenvolvimento para sua execução. Estes miniprojetos não precisam ser extensos, mas sim o suficiente para engajar o aluno no seu desenvolvimento colocando-o em contato com coisas novas. Pode compreender, por exemplo, pesquisa de um tema na internet usando recursos de livre escolha para sua apresentação, descrição de catálogo de componentes/serviços de livre escolha, pesquisa sobre empresa de livre escolha, resolução de um problema ligado à disciplina de livre escolha, etc.

\subsection{Atividades práticas e tutoriais}

As atividades práticas são atividades mais complexas de demandam um maior tempo que envolvem o domínio de certa ferramenta ou conhecimento e sua colocação na prática para analisar ou resolver certo desafio tecnológico/científico. Estas ferramentas podem envolver o uso de programas comerciais, livres ou de código aberto para desenvolvimento de certo projeto. Como etapa preliminar, o professor precisa fornecer ao aluno os conhecimentos teóricos de engenharia suficientes por trás dos programas a serem usados para não transformar as atividades práticas em mera repetição de passos. Em seguida vem o aprendizado do uso do programa a ser usado o qual pode ser realizado por meio de tutoriais genéricos em forma de vídeo que podem ser elaborados pelo professor e reforçados com tutoriais adicionais encontrados na internet. Dependendo da complexidade da atividade prática, esta pode ser dividida em várias etapas (e entre vários alunos) de forma a estas etapas serem desenvolvidas ao longo da disciplina junto com as aulas teóricas. Um aspecto muito importante é, se possível, permitir a livre escolha do tema de trabalho por parte do aluno. Temas específicos e alinhados com os interesses particulares dos alunos, em geral, trazem maior engajamento e melhores resultados. Figura 4 apresenta imagens das etapas do projeto CAD/CAE/CAM de componente de livre escolha de aluno para modelamento sólido, análise de engenharia e simulação de fabricação por usinagem. Já na Figura 5 é mostrado um dos tutoriais gravados em vídeo e postados no youtube.com sobre a atividade relacionada à simulação de usinagem CNC com ferramentas CAM.

Figura 4 - Trabalho prático de projeto CAD/CAE/CAM
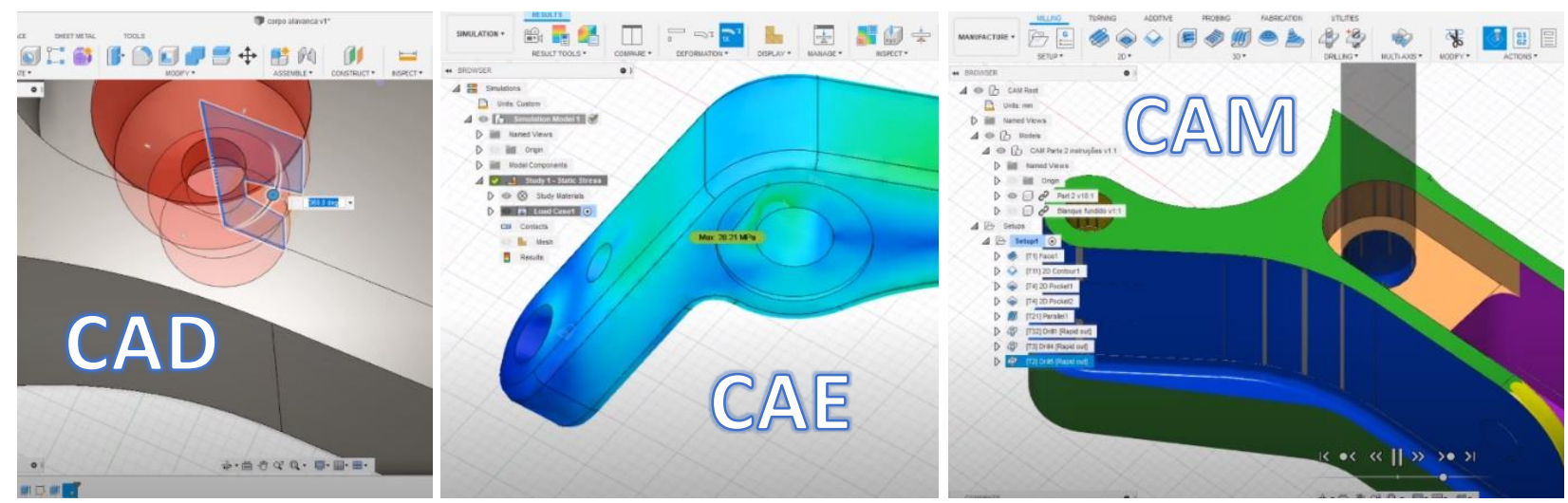

Fonte: próprio autor 
Figura 5 - Tutoriais desenvolvidos em forma de vídeo com instruções do professor e postados no youtube.

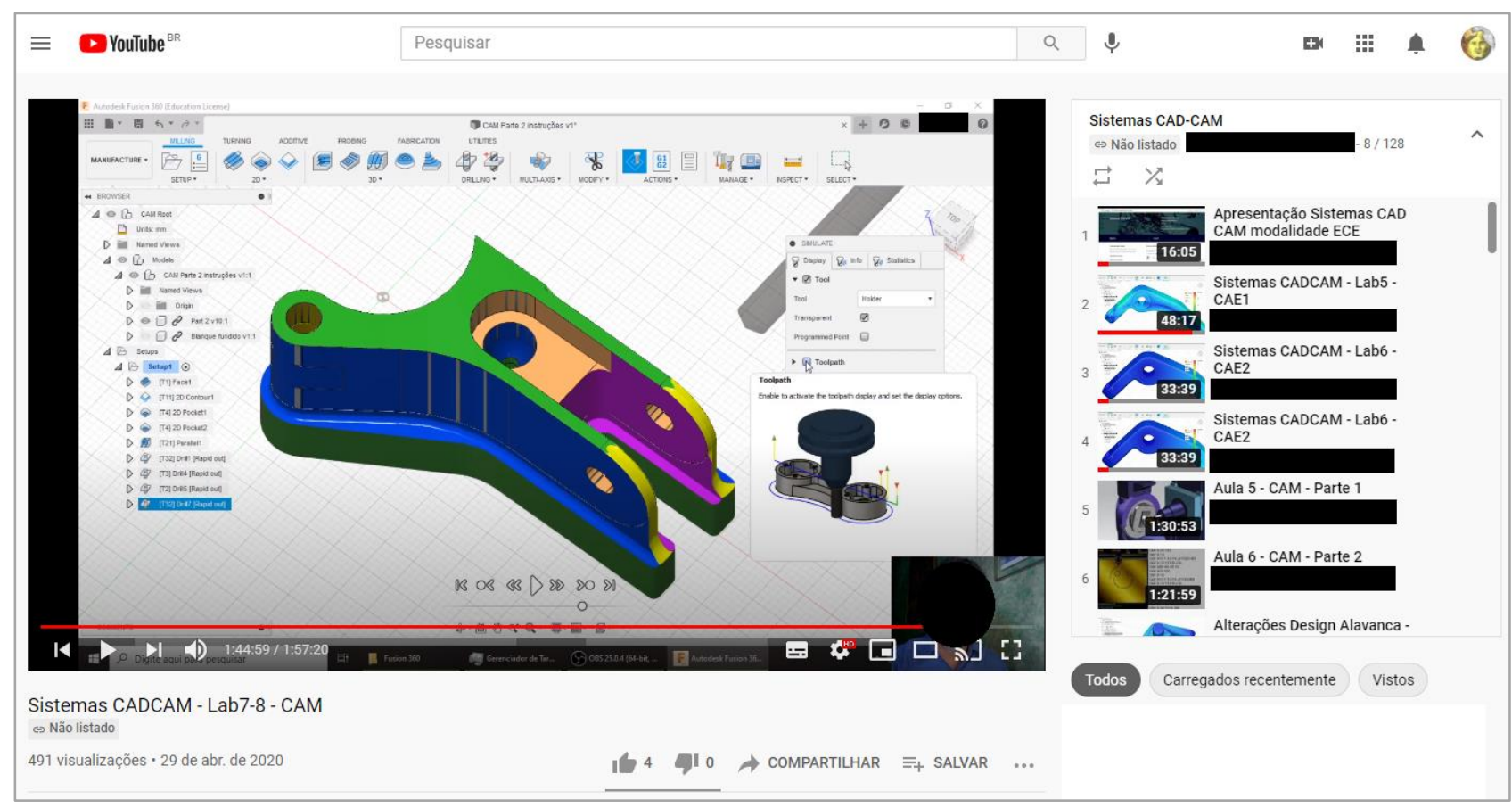

Fonte: próprio autor - youtube.com

\subsection{Relatórios}

A elaboração de relatórios é muito importante na formação do professional de engenharia considerado que a comunicação escrita é chave na transferência/documentação de informação técnica e científica. $O$ desenvolvimento de trabalhos na forma de relatórios demanda bastante tempo pelo qual é uma modalidade de trabalho que se presta para plágio levando em conta a grande quantidade de informação disponível na internet e a grande quantidade de sites que o facilitam. Nesse sentido, particularmente acredito que relatórios podem ser muito bem utilizados como meio para o aluno descrever o trabalho desenvolvido nas atividades práticas, ou seja, como uma forma de consolidar e sumarizar toda a caminhada realizada em atividades práticas de várias etapas.

\subsection{Apresentação oral}

A apresentação oral é uma das ferramentas de avaliação que evidenciam de forma muito clara o conteúdo assimilado pelo aluno. Quando se leva a apresentação oral ao formato digital (particularmente como vídeo gravado), a interação entre professor e aluno durante a apresentação é perdida, mas outros aspectos importantes podem ser ressaltados e até ser considerados como parte da avaliação como, por exemplo, o domínio do tema por parte do aluno, a coerência da apresentação, a didática utilizada e o conteúdo. Uma apresentação é um trabalho demorado, especialmente se o aluno não tiver familiaridade com as ferramentas de gravação de vídeo e edição. Programas como o MS Powerpoint já contam com ferramentas de gravação de aula junto com os slides de apresentação. Outros programas de gratuitos como o OBS Studio tem ferramentas de gravação muito completas para usar diversos recursos do computador. Nesse sentido, a produção de uma apresentação digital pode ser usada como forma de avaliação final. 


\section{CONSIDERAÇÕES FINAIS}

Neste trabalho, várias estratégias para avaliar o desempenho de um aluno em aulas ministradas a distância foram apresentadas. Estas estratégias são apresentadas como alternativas tanto para corroborar a assiduidade dos alunos às aulas como para mensurar seu desempenho na disciplina como um todo. Para avaliar a assiduidade dos alunos às aulas a distância e manter eles continuamente engajados, alternativas de avaliação de curta duração são integrados logo após cada aula para serem desenvolvidos. Já outras alternativas de avaliação de maior duração são objetivadas para avaliar o desempenho na disciplina toda na forma de projeto ao longo da disciplina ou trabalho final.

Por outro lado, e provavelmente, uma das maiores dificuldades para o professor é de disponibilizar de tempo suficiente para poder elaborar melhor estas dinâmicas, para revisá-las e para dar feedback apropriado aos alunos. Essa alta demanda de tempo pode ser atenuada com a colaboração de alunos monitores na disciplina para lidar com tarefas como dar feedback aos alunos, revisar avaliações e até para produzir alguns vídeo-tutoriais para uso das ferramentas computacionais que eventualmente possam ser usadas.

De qualquer maneira, é importante frisar que inevitavelmente a pandemia do Covid19 gerou um choque no modo de operação de toda a comunidade acadêmica exigindo aos agentes de educação a transição de um regime de 100\% de aulas presenciais para $100 \%$ de aulas virtuais. Nesse sentido, a universidade como instituição tem a responsabilidade de prover ferramentas, plataformas virtuais e treinamento adequados aos professores e educadores em geral para poder realizar esta transição de uma forma menos traumática e no menor tempo possível (NETEL, 2020). Vale salientar que cabe também ao professor a responsabilidade ir atrás desta capacitação para se aprimorar e encontrar meios para poder continuar lecionando com qualidade num regime de trabalho, muitas vezes, completamente diferente ao que está acostumado, isso enquanto durar as restrições de isolamento social impostas pela situação pandêmica atual.

\section{REFERÊNCIAS}

NETEL. Planejamento cursos virtuais: como organizar a sua disciplina. Universidade Federal do ABC, curso de extensão, ago. 2020.

PILETTI, Claudino. Didática geral. São Paulo, Ática, 1987.

PIMENTEL, Mariano; DE CARVALHO, Felipe da Silva Ponte. Princípios da Educação Online: para sua aula não ficar massiva nem maçante! SBC Horizontes, mai. 2020, ISSN 2175-9235. Disponível em: http://horizontes.sbc.org.br/index.php/2020/05/23/principioseducacao-online. Acesso em 01 abr. 2021.

ROCHA, Enilton Ferreira. Avaliação na EaD: estamos preparados para avaliar? Associação Brasileira de Educação a Distância, Textos EAD, mai. 2014. Disponível em: http://www.abed.org.br/arquivos/Avaliacao na EaD Enilton Rocha.pdf. Acesso em 12 abr. 2021.

SEVERO SANTOS, João Francisco. Avaliação no Ensino a Distância. Revista Iberoamericana de Educación, v.38, n.4, p.1-9, 2006.

ZABALA, Antoni. A prática educativa: como ensinar. Reimpressão 2010, Editora Artmed, 1998. 


\title{
ASSESSMENT STRATEGIES IN DISTANCE-LEARNING ENGINEERING COURSES: FINDING SOLUTIONS DURING COVID-19 PANDEMIC
}

\begin{abstract}
The current pandemic situation ended up changing abruptly the way of teaching engineering, forcing lecturers to adopt distance-learning education. Several technological tools for virtual communication and online videos ended up enabling accessibility of the classes to students. However, the assessment of the assimilation of class content by the student emerges as one of the biggest challenges, especially for teachers with lack of familiarity with distance-learning. In this work thirteen strategies are presented for the assessment of students enrolled in distance classes developed specifically for mechanical engineering courses. The introduction of these tools showed a great interest, engagement and good acceptance from the students reflected not only in a better performance, but also in the high quality of the resulting works.
\end{abstract}

Keywords: assessment strategies, distance-learning education, engineering 